University of St. Thomas, Minnesota

UST Research Online

\title{
$9-2011$
}

\section{Exploration of Sales-Marketing Interface Nuances in Saudi Arabia}

Avinash Malshe

University of St Thomas, amalshe@stthomas.edu

Jamal Al-Khatib

university of st.thomas, jaalkhatib@stthomas.edu

Mohammed Al-Habib

King Abdul Aziz University

Shaza Ezzi

King Abdul Aziz University

Follow this and additional works at: https://ir.stthomas.edu/ocbmktgpub

Part of the Marketing Commons

This Article is brought to you for free and open access by the Marketing at UST Research Online. It has been accepted for inclusion in Marketing Faculty Publications by an authorized administrator of UST Research Online. For more information, please contact asle4660@stthomas.edu. 


\title{
Exploration of sales-marketing interface nuances in Saudi Arabia
}

\author{
Avinash Malshe ${ }^{\mathrm{a}, *}$, Jamal Al-Khatib ${ }^{\mathrm{a}, 1}$, Mohammed Al-Habib ${ }^{\mathrm{b}, 2}$, Shaza Ezzi ${ }^{\mathrm{b}, 3}$ \\ a Opus College of Business, University of St. Thomas, St. Paul, MN, United States \\ ${ }^{\mathrm{b}}$ Faculty of Economics and Administration, King Abdulaziz University, Jeddah, Saudi Arabia
}

\section{A R T I C L E I N F O}

\section{Article history:}

Received 8 July 2010

Accepted 5 August 2011

Available online $\mathrm{xxxx}$

\section{Keywords:}

Sales-marketing interface

Qualitative

Saudi Arabia

Culture

Power

\begin{abstract}
A B S T R A C T
Extant research on sales-marketing interface has ignored emerging markets as research contexts. This study uses grounded theory methodology and depth-interview data from 37 sales and marketing professionals in Saudi Arabia to explicate how firm contexts that are influenced by Islamic values may shape intraorganizational mechanisms between firm leadership and sales and marketing departments, moderate their roles in marketing strategy activities, and affect interface dynamics. Specifically, appreciation of high power distance and traditional authority allow top leadership to be extensively involved in firm's everyday operations and there is a conspicuous absence of two-way dialog between top leadership and interface personnel. As a result, marketing strategy making authority is rarely transferred to sales and marketing. The context thus creates a chain of command with top leadership holding central authority, marketers preparing action plans and salespeople implementing those plans. Overall, this context brings forth certain hitherto unexplored perspectives on this interface.
\end{abstract}

(c) 2011 Elsevier Inc. All rights reserved.

\section{Introduction}

Business organizations often rely on customer-facing departments such as sales and marketing to create, communicate, and deliver differentiated value propositions. Given the revenue generation responsibility these departments share in today's hypercompetitive business environment, firms expect the interface between sales and marketing to be optimal so that they can maintain competitive advantage in the marketplace (Guenzi \& Troilo, 2007; Krohmer, Homburg, \& Workman, 2002; Malshe \& Sohi, 2009a).

Sales-marketing interface (henceforth interface) literature highlights many critical factors that can either contribute to or hamper the optimal functioning of this interface. Specifically, research highlights the importance of interface integration, cooperation, collaboration, and communication in this regard. Further, scholars suggest that organizational structures, cultures, systems, processes, and peoplerelated elements may impact how this interface functions (Dewsnap

\footnotetext{
the authors acknowledge the research assistance provided by the graduate students in the Faculty of Economics and Administration at King Abdulaziz University. They also acknowledge helpful comments from Wim Biemans and Michael Krush on the earlier drafts of this manuscript. They also acknowledge constructive comments of the reviewers.

* Corresponding author. Tel.: + 16519624287.

E-mail addresses: amalshe@stthomas.edu (A. Malshe), jaalkhatib@stthomas.edu (J. Al-Khatib), habib@kau.edu.sa (M. Al-Habib), shazaezzi@yahoo.com (S. Ezzi).

1 Tel.: + 16519625126 .

2 Tel.: + 966505618513

3 Tel.: +966 26952000.
}

\& Jobber, 2000, 2002; Homburg, Jensen, \& Krohmer, 2008; Le Meunier-FitzHugh \& Piercy, 2007; Rouziès et al., 2005).

As one examines interface literature, one cannot help but notice that most studies on this interface have used samples from the US, European Union, or Australia and New Zealand. The commonality across these research contexts is that they are developed economies that share Western European cultural origin, which shapes their way of life. As a result, current understanding of this interface has remained context-specific. This is consistent with Burgess and Steenkamp (2006, p.337) who note: “...our knowledge of marketing phenomena derives almost exclusively from research conducted in high income, industrialized countries."

Research in the area of international business highlights how societal culture as well as the characteristics of emerging markets impact organizational mechanisms, organizational members' roles, and their interactions (Abdul-Muhmin, 2005; Huff \& Smith, 2008; Kulviwat, Bruner, \& Al-Shuridah, 2009; Laroche, 2009; Li \& Zhou, 2010; Liu, Luo, \& Shi, 2003; Yavas, Cavusgil, \& Tuncalp, 1987; Zhou \& Li, 2010). This evidence suggests that studying the interface nuances in different national or cultural contexts may bring forth the hitherto unexplored perspectives on this interface.

Saudi Arabia (henceforth Saudi) is a case in point. Saudi has a unique societal culture shaped by Islamic values, status hierarchy, and notions of high power distance that may affect how intraorganizational entities interact with one another (Bhuian, 1998). Further, Saudi is an emerging economic powerhouse (CIA Factbook, 2010). As Burgess and Steenkamp (2006, p.337) note, "Emerging markets present significant departures from the assumptions of theories developed in the Western world that challenge our conventional 
wisdom" and hence it is "paramount for the future of marketing science and practice that we conduct more research in so-called emerging markets." Consistently, this paper examines the organizational mechanisms and interface dynamics within Saudi Arabia that not only is an emerging market, but also represents a non-western context influenced by Islamic values. In doing so, this paper aims to expand theoretical boundaries of the interface literature.

The next section contains a brief overview of the interface literature as well as how cultural elements shape business practices in Saudi. Methodology and detailed findings follow this section. The paper concludes with a discussion of theoretical contributions, managerial implications, and study limitations and future research.

\section{Background}

\subsection{Sales-marketing interface}

Extant literature on sales-marketing interface suggests that in many firms the working relationship between sales and marketing remains sub-optimal (Kotler, Rackham, \& Krishnaswamy, 2006). Relatedly, major focus of the early interface literature remained on understanding factors that may (a) hamper the smooth functioning of this interface such as interfunctional conflicts, differences in sales and marketing thought worlds, sub-cultures, and lack of goal and compensation alignment, or (b) contribute to its optimal functioning such as enhanced interface integration, collaboration, or cooperation (Beverland, Steel, \& Dapiran, 2006; Dawes \& Massey, 2005; Homburg \& Jensen, 2007; Maltz, 1997; Matthyssens \& Johnston, 2006).

The more recent work in this area has studied (a) how sales and marketing may successfully create marketing strategies, (b) how marketers may enhance their credibility in salespeople's eyes, or (c) how marketers may gain buy-in for their strategies from the sales force. This work also suggests that different firms may organize their sales and marketing functions differently, which may impact the interface dynamics (Biemans, Makovec-Brenčič, \& Malshe, 2010; Malshe, 2010; Malshe \& Sohi, 2009a, 2009b).

In summary, extant interface research shows that some differences between sales and marketing are here to stay since these differences emanate from different roles and responsibilities. Nonetheless, organizations may institute cross-functional processes, strategic and operational integrative devices, or joint sales-marketing taskforces to harmonize this interface (Dewsnap \& Jobber, 2009; Piercy \& Lane, 2003). Additionally, firms may also aim to reduce turf barriers, intergroup differentiation, and intercultural and philosophical differences within this interface by engendering greater interface trust and cooperation (Hutt, 1995; Ingram, 2004; Oliva, 2006; Piercy \& Lane, 2003).

\subsection{Saudi Arabia: culture and business practices}

Hofstede $(1980,1991)$ proposes four cultural dimensions: power distance, uncertainty avoidance, individualism, and masculinity/ femininity to investigate nuanced differences among societies. Power distance refers to the extent to which individuals accept unequal power distribution in institutions. Uncertainty avoidance refers to the extent to which people can tolerate ambiguous situations. Individualism/collectivism refers to the degree to which people prioritize self-interests over interests of those that belong to their immediate social circle- that is, their in-group. Last, masculinity/femininity dimension refers to whether societies emphasize masculine values such as assertiveness and competitiveness over feminine values such as being accommodating, valuing trust, or maintaining a caring attitude toward others.

Hofstede highlights that Saudi Arabia scores high (86/100) on power distance indicating deep social divisions of power with limited interaction and movement between social classes. Relatedly, Harris and Moran (1987) note that Saudi business culture, which is influenced by Islamic traditions, is not only high power distance but also the one that recognizes status hierarchy. One often finds that top managers within Saudi firms make decisions autocratically, and subordinates look up to superiors for guidance. In addition to one's position on the organizational hierarchy, many Saudi managers may possess informal power that typically originates from family connections (Bhuian, 1998).

Saudi scores somewhat high (68/100) on uncertainty avoidance, which suggests that Saudis like to go by the rulebook to reduce risks and uncertainty. This may explain why Saudi managers are not tolerant of employees' spontaneous actions or deviation from the formal rules (Bjerke \& Abdulrahim, 1993; Muna, 1980). As such, Saudi firms follow centralized decision-making practices (Baker \& Aboulsmail, 1993) with top management exerting strong control and minimizing any deviations. Further, being less tolerant of ambiguity, Bhuian (1998) notes that Saudi managers tend to avoid conflicts and when necessary deal with conflicts and the resultant ambiguity in an authoritarian manner.

Saudis score low (50/100) on masculinity/femininity index indicating that they somewhat value competition and performance. Last, Saudis are low (36/100) on individualism dimension indicating that Saudi managers put group well-being and progress before individual gains. With respect to the last two dimensions, Saudi organizations resemble clan organizational forms that (a) have organic solidarity; (b) employ a system of traditional authority; (c) place great emphasis on norms and common values; and (d) work to reduce the distinctions between individual and organizational goals (Ouchi, 1980).

Overall, the literature review on Saudi business practices brings forth how Saudi culture has a significant impact on the roles and responsibilities of different intra-organizational entities and how they interact with each other. Given that the extant knowledge of salesmarketing interface comes from only using samples drawn from developed, western contexts; conducting an in-depth investigation of this interface in an emerging market such as Saudi Arabia is likely to test interface theory's assumptions and advance this literature in a meaningful way.

\section{Methodology}

The lack of extant theoretical frameworks on this interface in Saudi context motivated us to conduct a qualitative study and collect interview data using theoretical sampling technique (Strauss \& Corbin, 1990). Theoretical sampling is a purposive, non-random sampling technique that requires researchers to look for informants and settings that would allow them to maximize the discovery of variations among concepts during data collection (Creswell, 2007; p. 240-41).

The research team began recruiting interview informants using personal contacts at mid-to-senior levels within different companies (Tuli, Kohli, \& Bharadwaj, 2007). Further, referral and snowballing techniques helped us to contact additional informants. Overall, out of the 41 sales and marketing professionals that the researchers approached, four declined the interview request owing to reasons of confidentiality and/or company policy. The final informant pool consists of 37 sales and marketing professionals. All informants were Saudi nationals and each informant had been in his/her current job for at least 2.5 years.

All informant companies were either Saudi owned or controlled, and had between 100 and 400 employees. Their annual sales ranged between $\$ 100$ and 250 million and they operated in business to business environment. Each company in the sample had independent marketing and sales departments. The principles of theoretical sampling directed us to purposefully sample from companies and industries that would represent varying degrees of growth rates, industry competitiveness, and environmental uncertainty (See Table 1).

The discovery-oriented interviews (Deshpande, 1983) lasted between 40 and $110 \mathrm{~min}$. The researchers conducted each interview at the respondent's workplace, in the privacy of their office, at a time 
Table 1

Informant characteristics.

\begin{tabular}{|c|c|c|}
\hline & Marketing & Sales \\
\hline Organizational & Junior-Marketing (4 females) & Junior-Sales (3 males) \\
\hline level/Function/Gender/Job & -Marketing executive, marketing coordinator & Sales representative, field sales manager \\
\hline \multirow[t]{4}{*}{ Titles } & Middle- Marketing ( 7 males and 2 females) & Middle- Sales ( 5 males and 1 female) \\
\hline & -Marketing manager, Senior marketing executive & Area sales manager \\
\hline & Senior- Marketing ( 7 males and 2 females) & Senior- Sales ( 6 males) \\
\hline & -Marketing director, senior marketing manager, business director & VP-sales, senior sales manager, senior sales executive \\
\hline Industries represented & $\begin{array}{l}\text { IT, Industrial products, Manufacturing, Packaging, Consumer products, } \\
\text { Marketing services, Pharmaceuticals }\end{array}$ & $\begin{array}{l}\text { Hospitality, Pharmaceuticals, Transportation, Manufacturing, Consumer } \\
\text { products, Industrial products, Telecom }\end{array}$ \\
\hline \multirow[t]{2}{*}{ Education } & Undergraduate degree: $60 \%$ & Undergraduate degree: $55 \%$ \\
\hline & Graduate or higher degree: $40 \%$ & Graduate or higher: degree: $45 \%$ \\
\hline \multirow[t]{2}{*}{ Org tenure } & $2.5-5$ years: $35 \%$ & $2.5-5$ years: $25 \%$ \\
\hline & Over 5 years: $65 \%$ & Over 5 years: $75 \%$ \\
\hline
\end{tabular}

convenient to him/her. Since all informants spoke English, the researchers conducted all interviews in English using the pre-tested interview protocol (See Appendix 1). Further, the interviewers allowed informants to offer examples and anecdotes as they spoke and asked questions to clarify ambiguities and prevent interviewer-induced interpretation bias (McCracken, 1988). After 37 interviews, theoretical saturation was achieved (Strauss \& Corbin, 1990).

To counter the potential for informant bias or socially desirable responses, the research team took three specific steps. First, before starting the interview the researchers made clear to the informants that they would not be seeking any confidential information from the informants. Next, informants received an assurance that (a) the interview data would be kept strictly confidential, (b) only the research team would have access to their interview tapes and transcripts, and (c) their or their company's name would not appear anywhere in the papers published using the interview data. Last, the research team promised to share overall research findings with the informants.

Data and transcription management was done using NVivo. Data analysis began with open coding (Corley \& Gioia, 2004) that focused on the language used by informants to identify first-order codes. The next step was axial coding. In this step, the researchers investigated relationships among the first-order codes to group them under higher-order themes, which helped them arrive at the findings.

To insure data trustworthiness and analytical rigor (Lincoln \& Guba, 1985), the research team asked two independent judges to evaluate the coding of 14 randomly selected interviews. The team then calculated the proportional reduction in loss based on the judges' agreement or disagreement with our coding. The proportional reduction in loss was 0.87 , which is well above the 0.70 cut-off level recommended for exploratory research (Rust \& Cooil, 1994). Next, an independent qualitative researcher audited interview protocol, coding, and random samples of interview transcripts to assess whether the conclusions reached were plausible. There was a significant degree of agreement between this researcher's assessment and that of the team's. Last, member checks helped us vet data interpretations and findings (Creswell, 2007; p. 208).

\section{Findings}

Study findings indicate that within the paternalistic, high power distance Saudi culture; top leadership is extensively involved in the day-to-day operations of Saudi firms. Their level of involvement impacts various organizational mechanisms and processes. In particular, there is a conspicuous lack of two-way communication between top leadership and customer-facing departments such as sales and marketing regarding marketing strategy issues. Further, top leadership micro-manages sales and marketing functions and rarely devolves marketing strategy making authority to these functions. Such organizational dynamics give rise to an explicit chain of command within Saudi firms with top leadership holding central decision-making authority, marketers being in charge of preparing marketing action plans and serving as overseers of strategy implementation, and salespeople being the actual implementers of strategy. Overall, the contextual roles sales and marketing play bring forth certain nuances of interface dynamics that have not been documented in the extant literature. Below, findings are discussed in greater detail.

\subsection{High power distance and status hierarchy facilitate centralized decision-making}

Data analysis suggests that top-level organizational leaders in Saudi are extensively involved in devising firms' marketing strategies. High power distance facilitates centralized decision-making practices and allows Saudi organizational leaders to exert authoritarian control over their firms' marketing strategy and tactical activities. Many of our informants mentioned how tightly their leaders managed every aspect of their marketing strategies.

Our leaders like to be involved...they decide on the major strategic initiatives every year and are always there to guide us in every step...they scrutinize our activities and make sure everything works according to their planned strategies. [Rahim, Male, Senior Sales Executive, Telecom].

Senior leadership plans our strategies...it is their prerogative. [Sultana, Female, Marketing executive, Manufacturing].

Informants suggested that firm leaders not only conceptualized various strategic marketing initiatives but also adopted a very hands-on approach by keeping a close watch over how firm's strategies were implemented on a day-to-day basis (Bhuian, 1998; Harris \& Moran, 1987).

Our board of directors plans all the business strategies for the firm to maximize profit. They then give us [marketing] directives in terms of how to put plans in place so that we can achieve profit maximization. They then constantly follow-up with us about the extent of success their planed strategies have had over the year. [Basem, Male, Marketing Director, Industrial Products].

\subsection{Centralized decision-making moderates firm dynamics and authority dissemination to interface personnel}

Data suggest that since Saudi firms are run in an authoritarian manner, top management rarely seeks input from either sales or marketing personnel before devising major marketing strategies. Thus, an important feature of organizational mechanisms within Saudi firms is a conspicuous absence of two way dialog between firm leadership 
and sales/marketing during the process of marketing strategy making. Kasim's quote is pertinent here.

We do not have the opportunity to offer any input when our leaders work on finalizing the strategy. In the many years that I have worked here, I have never been asked for a feedback in the strategy process. [Kasim, Marketing Executive, Packaging, Male].

Once strategies are finalized, top management shares those with marketers. In particular, marketers are presented with a rigid strategy framework and directed to prepare action plans that translate strategies into specific activities. Study informants highlight that every element of their plans is scrutinized by firm leadership. In the event that certain aspects of their plan are not approved, marketers do not have the opportunity to voice their opinions. PK notes:

Our major task is to prepare marketing action plans based on the strategic direction we receive. The way we work is after we make our plans we submit them to our leaders for their approval. They have the right to reject some activities that they do not like...once they approve the action plan, we get a go ahead. [PK, Male, Senior Marketing Executive, Pharmaceuticals].

Overall, this finding indicates that within Saudi context, marketing strategy making authority is rarely transferred to marketing or sales departments who are responsible for taking it to the final customers.

\subsection{Organizational dynamics within Saudi firms and its effects on sales and marketing's roles}

Saudi context characterized by centralized decision-making shapes marketing and sales personnel's roles in unique ways. Lacking marketing strategy making authority, Saudi marketers' primary responsibility revolves around preparing action plans that will translate top management's strategic agenda into implementable activities. As noted before, these plans are subject to top leadership approval. Sania explains the process in her firm below.

Based on the guidance provided by the top management, marketing manager in our firm plans for new methods of implementing the plans. These methods are then revised, discussed, edited and approved by boards of directors. After these deliberations, the new improved methods are sent back to the marketing manager and finally these methods are applied by the marketing team. [Sania, Female, Marketing Executive, Marketing Services].

The second task Saudi marketers perform is overseeing and insuring the proper implementation of action plans. Here, marketers act as coordinators that bring together the required resources such as marketing materials, communication plans, or product samples for successful plan implementation. They also closely monitor, control, and direct salespeople's field activities from time to time. Kasim's quote highlights that one of the important jobs marketers perform is to insure that the top management strategies are carried out appropriately.

Main responsibility for the implementation of marketing strategy that has been crafted by the top management rests with the marketing department. The top management keeps track of market developments and results, and it also insures and supervises the availability of resources required for implementation. [Kasim, Male, Marketing Coordinator, Consumer Products].

The third task marketers perform is that of serving as a link between the top management and marketplace. In this role, they are responsible for appraising the top management of their firm's market successes and/or failures, and also transmitting any feedback from sales personnel.
Analyzing salespeople's activities suggests that they are never a part of strategy discussion either. Their primary task is to insure that all the activities outlined in the marketing action plan are carried out in the field. Specifically, salespeople follow marketers' directives and select target customers, meet with those customers, communicate marketing message, manage field inventories, and collect competitive information. Data suggest that salespeople have little flexibility to deviate from the action plans and they are constantly watched over by not only their marketing colleagues but by top management as well. The following two comments bring forth how salespeople must insure that top management strategies are wholeheartedly implemented.

Our primary responsibility is to make sure that we follow the marketing action plans and perform the needed tasks. Action plans are our blueprints...accordingly we select customers, meet with them, and promote our products in the market. Our activities are welldefined and there is not much room for deviation. [Anwar, Male, Area Sales Manager, Consumer Products].

Salespeople's job is to follow implementation guidelines offered by marketing so that we are able to implement the marketing initiatives. [Tariq, Male, sales Representative, Transportation].

Overall, the examination of Saudi marketers' and salespeople's roles points to the presence of explicit chain of command with top leadership setting the agenda, marketers translating it into action plans, and salespeople implementing those plans in the field. This chain is unique in that information (in the form of directives) flows in only one direction - from the top to the bottom, with the middle or lower levels rarely having any opportunity to ask questions, object, or provide constructive feedback.

\subsection{How do sales and marketing's respective roles affect interface dynamics?}

Data analysis suggests that the characteristics of Saudi organizational dynamics and the resultant nature of sales and marketing's roles lead to unique interface dynamics- something that is not observed in western contexts. Four major areas are highlighted below.

Since marketers create action plans based on strategies outlined by top leadership and serve as a link between sales force and top leadership; sales organizations in Saudi view marketers as top management's extension. This perception within the sales force allows marketers to enjoy symbolic, non-coercive power (Gaski, 1984) over salespeople.

Khalida's quote indicates how she views sales to be a follower of marketers' directives.

We consider Marketing as a big umbrella... and under this umbrella, sales organization operates. Marketing sets the main activities for the year and salespeople's role is to follow marketing's directives. [Khalida, Female, Area Sales Manager, Hospitality].

Marketers are keenly aware of the purely symbolic nature of their power that is decoupled from any strategic authority (Fiss \& Zajac, 2004). This awareness makes them mindful that their success at insuring optimal strategy implementation depends greatly upon salespeople's cooperation. Hence, marketers make every effort to not alienate salespeople through words and/or actions. In many instances, marketing informants referred to salespeople as partners or brothers clearly indicating to salespeople of their status as in-group members (Hofstede, 1980, 1991). Hassan, a business director with marketing responsibility offers his perspective below.

We treat our salespeople as our key partners...they are an asset since they have information about the customer interaction and 
responses. They provide key insights to the marketing department. [Hassan, Male, Business Director, Pharmaceuticals].

Interface scholars highlight the acrimonious relationship and turf wars between sales and marketing (Dawes \& Massey, 2005; Homburg et al., 2008; Hutt, 1995). Such dynamics were absent within Saudi context. While study informants acknowledged the differences of opinion, their cultural orientation toward conflict avoidance led them to underplay the same. On the contrary, informants characterized their counterpart function as an in-group member, and emphasized the importance of teamwork, and unity as the quote below highlights.

Teamwork [between sales and marketing] is the keyword in our business. There is no way marketing department can achieve anything without the support of sales team. Our sales team is highly qualified and we act as a united group in generating business. [Fatima, Female, Marketing Director, Marketing Services].

Sultan, a marketing manager with a pharmaceutical company took a phone call during the interview to speak with one salesperson. After the conversation, he noted:

This person [I just spoke with] is one of our medical representatives. We work together as one team. I do not deal with him as if I am giving him instructions. We do not deal with each other as manager-salesperson...we are one team with everyone being equal. [Sultan, Male, Marketing Manager, Pharmaceuticals].

In addition to the absence of turf wars, data suggest that it is easier for firms to forge interface cooperation (Cespedes, 1993; Maltz, 1997). In some informants' firms, policy manuals had explicitly stated that salespeople were expected to cooperate with marketers. A quote from Rasheed, a senior marketing manager with an IT firm, brings forth this aspect.

In this company, the Sales and Marketing Executives' Manual establishes policies governing the company's sales and marketing standards and practices. These policies define management's arrangements for managing sales and marketing operations and activities expected of both these departments. These top-level policies represent the protocols for achieving and maintaining the efficient operation of the Sales and Marketing functional areas. [Rasheed, Male, Senior Marketing Manager, IT]..

Last, contrary to the reportedly problematic interface communication within western context (Kotler et al., 2006), study findings indicate that Saudi interface communication is frequent, formal, ritualistic, and follows established norms. This behavior is consistent with what one may expect to see in cultures with low tolerance for ambiguity and deviations from norms (Bhuian, 1998). The quote below highlights the formal and ritualistic elements of communication.

Anything we need from marketing, it has to be through our supervisor and he will contact the marketing department via e-mail with notifying the supervisor on what is needed. And this is the process that we follow. [AA, Male, Senior Sales Manager, Industrial Products].

\section{Discussion, contributions, and implications}

This study examines how a non-western, emerging market context where Islamic values motivate people to respect high power distance and traditional authority, avoid uncertainty, and emphasize norms and common values may impact organizational mechanisms and processes between firm leadership and customer-facing departments such as sales and marketing. The study further examines how these contextual characteristics may moderate sales and marketing personnel's roles, and resultant interface dynamics. The paragraphs below outline the specific theoretical contribution study findings make to the interface literature.

First, study findings bring forth how high-context cultures that respect power distance and status hierarchy facilitate centralized decision making and allow organizational leaders to exert authoritarian control over firms' strategic and tactical marketing activities. In such contexts, the much involved top leadership keeps a close watch over how firm's marketing strategies are translated into action plans and implemented on a day-to-day basis (Bhuian, 1998; Harris \& Moran, 1987). This relegates crucial customer-facing functions such as sales and marketing to simply following and executing top leadership agenda. Thus, in such contexts, organizational reality contrasts the prima facie appearance of sales and marketing departments having a clear charter and set of responsibilities (Homburg et al., 2008; Kotler et al., 2006).

Second, findings highlight how the extensive involvement of top leadership in everyday marketing activities (a) impacts the dynamics between firm leaders and interface personnel, and (b) affects delegation of strategy making authority to interface personnel. In particular, there is a conspicuous absence of a crucial organizational mechanismfrequent, two-way communication between the top leadership, and marketing and sales over marketing strategy and tactical issues. Top leadership presents marketers with a rigid strategy framework to work within, requires that marketers prepare consistent action plans for field-level execution of strategies, and scrutinizes their action plans with the right to reject the ones that they do not approve of. Overall, findings bring forth the characteristics of those organizational contexts that may strip interface personnel of marketing strategy making authority and reduce them to simply followers of directives.

Third, findings suggest that having been stripped of strategy making authority puts a unique spin on interface personnel's roles within firms. In particular, marketers perform the task of preparing action plans based on top leadership's marketing strategy, and insure its proper implementation by sales organization Salespeople in such contexts are expected to follow marketers' directives and perform implementation tasks such as selecting and meeting with target customers, communicating the message, and insuring adequate supply of products within the channels. Overall, this context creates an explicit chain of command within firms wherein strategic directives are handed down through the hierarchy. These directives are neither debated nor questioned; but simply implemented by interface personnel. Extant interface literature has not documented such roles and responsibilities of interface personnel.

Fourth, the context-specific roles sales and marketing personnel perform give rise to unique interface dynamics. In particular, salespeople's appreciation of high power distance and status hierarchy (Hofstede, 1980) allow marketers to enjoy symbolic power and command salespeople's activity compliance. Marketers, recognizing the purely symbolic nature of this power and their dependence on salespeople for successful strategy implementation, often portray them as in-group members and make every attempt to not alienate them. These findings contrast the prevalent themes of perceived social distinction within the interface literature (Homburg \& Jensen, 2007; Rouziès et al., 2005). Next, emphasis on uncertainty avoidance and maintenance of in-group harmony (Hofstede, 1980, 1991; Ouchi, 1980) compel Saudi interface managers to downplay any interface quibbles- a far cry from the documented open conflicts and turf wars within this interface (Dawes \& Massey, 2005). Findings also bring forth evidence of frequent, ritualistic, and formal communication within the interface, thus indicating that interface undercommunication (Kotler et al., 2006) may not be a problem area in certain contexts. Overall, these findings allow us to test extant interface theory's underlying assumptions (Burgess \& Steenkamp, 2006) 
and highlight how certain cultural contexts may alter interface personnel's roles and scope of activity and smoothen their interaction; even in the absence of specific efforts to engender interface harmony (e.g., Oliva, 2006; Rouziès et al., 2005).

The final contribution of this study is methodological. This paper is the first empirical study that the research team is aware of that situates extant knowledge of sales-marketing interface theory in an emerging market context that also has strong underpinning of Islamic values and culture. In doing so, this study responds to a call by Burgess and Steenkamp (2006), who exhort scholars to test the limits of existing theories in newer contexts as a first step in new theory development (p.339). Further, given the complexity and difficulty of data collection in the Gulf region including Saudi, the use of grounded theory methodology and colleting in-depth interview data is a methodological contribution to the interface literature.

The findings of this study offer the following managerial insights. First, even today, Saudi firms depend on expatriate managerial talent (CIA Factbook, 2010). In this regard, study findings may help the newly hired non-Saudi marketing and sales executives to familiarize themselves with how societal culture and values may affect organizational dynamics between top leadership and interface personnel, and their roles and responsibilities. Second, the findings, when examined collectively suggest that when working in different cultural contexts, interface managers must be mindful about how the underlying, nonapparent context variables may impact their roles and responsibilities as well as interface dynamics related to communication, cooperation, collaboration and power balance. Such an understanding may help them work through the intricacies of interface functioning in various cultural contexts and achieve strategic success. Last, findings show that when sales and marketing personnel are obligated to work toward fulfilling common goals (top management's goals in this context); that takes away the often-found acrimony within the interface and creates a smooth interface relationship. While the lack of strategic authority with either sales or marketing helps achieve smooth interface functioning in Saudi context; managers may use this finding to establish organizational systems and processes that, while not taking their strategic power away, can create common goals for the interface personnel thereby improving its day-to-day functioning.

\section{Limitations and future research}

The qualitative nature of this study is its strength. However, one may argue that spending time with managers in their natural settings, instead of conducting depth-interviews, would have given us deeper insights into the interface dynamics. In response, it is worth noting here that scholars have used different qualitative methodologies to investigate strategic phenomena (Bush, Bush, Orr, \& Rocco, 2007; Jarratt \& Fayed, 2001; Kniazeva \& Belk, 2010; Wang \& Netemeyer, 2004). Second, one may question whether conducting interviews in Arabic would have given us better insights. While meritorious, this approach would require us to back-translate interview transcripts into English for the purpose of using informant quotes in our findings. This could potentially make the data susceptible to loss of meaning in translation. Third, a sample of 37 Saudi nationals from Saudi-owned/controlled firms may be considered small, under-representing females, and non-generalizable. Readers may view the sample in the light of data collection difficulties in emerging markets and relative under-representation of women in managerial workforce in such contexts (Burgess \& Steenkamp, 2006; Mcevers, 2008). As regards the number of informants, Creswell (2007; p.66-67) suggests that theoretical saturation may be reached after 20-30 interviews. Fourth, the sample was drawn from firms in business to business settings. It is likely that a great deal of similarity in the configuration of sales-marketing interfaces in business firms (Homburg et al., 2008) may be the reason why we did not find a significant degree of variance in the functional roles of sales and marketing people in study data.
Fifth, our sample does not contain dyadic data, which would allow us to hear perspectives of both sides from within the same firm. Next, it is quite well known that in many Saudi firms, owners or other powerful families hold strong position in the organization. This may compel informants to exercise extreme caution and offer socially desirable responses that would not paint a negative organizational picture. To proactively address this potential bias, elaborate steps as outlined in the methodology section earlier were employed. Last, the use of individual informants to study organizational phenomenon, although a common practice in business research, is a potential limitation. Member checks helped us insure the validity of findings and address the level of analysis issues.

This study is the first step in the exploration of the nuances of sales-marketing interface in emerging market contexts. Future studies may use other cultural and/or market contexts as well as other methodologies to validate study findings, or explore additional facets of this interface. Given that rapid changes in emerging markets may force firms to become more market-oriented, future scholars may conduct longitudinal studies to understand how changes in various market characteristics may affect the roles and responsibilities of sales and marketing, and interface functioning. Data for this study came from firms in business markets. As Homburg et al. (2008) have shown earlier, this may account for the lack of variance in our findings regarding the roles and responsibilities of sales and marketing. In future, scholars may examine whether the interface dynamics differ between B2B and B2C firms in such contexts. Future research may also compare the interface dynamics between foreignowned/controlled and nationally-owned/controlled firms. This would allow us to understand the compounded effect of national culture and parent organizational philosophy on various firm mechanisms and interface functioning.

\section{Appendix 1}

What are the primary roles and responsibilities of salespeople in your company?

What are the primary roles and responsibilities of marketers in your company?

How are marketing strategies created within your company? What role do salespeople play in this process? What role do marketers play in the process?

Please comment on the interactions between sales and marketing departments in your firm on a day-to-day basis.

\section{References}

Abdul-Muhmin A. Instrumental and interpersonal determinants of relationship satisfaction and commitment in industrial markets. J Bus Res 2005;58(5):619-28.

Baker M, Aboulsmail F. Organizational buying behavior in the gulf. Int Mark Rev 1993 42-60.

Beverland M, Steel M, Dapiran G. Cultural frames that drive sales and marketing apart: an exploratory study. J Bus Ind Mark 2006;21:386-94.

Bhuian S. An empirical examination of market orientation in Saudi Arabian manufacturing companies. J Bus Res 1998;43(1):13-25.

Biemans W, Makovec-Brenčič M, Malshe A. Marketing-sales interface configurations in B2B firms. Ind Mark Manage 2010;39(2):183-94.

Bjerke B, Abdulrahim A. Culture's consequences: management in Saudi Arabia. Lead Org Dev J 1993;14(2):30-5.

Burgess S, Steenkamp JBEM. Marketing renaissance: how research in emerging markets advances marketing science and practice. Int J Res Mark 2006:23(4):337-56.

Bush A, Bush V, Orr L, Rocco R. Sales technology: help or hindrance to ethical behaviors and productivity? J Bus Res 2007;60(11):1198-205.

Cespedes F. Coordinating sales and marketing in consumer goods firms. J Consum Mark 1993;10:37-55.

CIA Factbook. . Accessed fromhttps://www.cia.gov/library/publications/the-worldfactbook/geos/sa.html2010.

Corley K, Gioia D. Identity ambiguity and change in the wake of a corporate spin-off Admin Sci Quart 2004;29:173-208.

Creswell J. Qualitative inquiry and research design. Sage; 2007.

Dawes P, Massey G. Antecedents of conflict in marketing's cross-functional relationship with sales. Eur J Mark 2005;39:1327-44. 
Deshpande R. Paradigms lost: On theory and method in research in marketing. J Mark 1983;47:101-10.

Dewsnap B, Jobber D. The sales-marketing interface in consumer packaged-goods companies: a conceptual framework. J Pers Sell Sales Manage 2000;20:109-19.

Dewsnap B, Jobber D. A social psychological model of relations between marketing and sales. Eur J Mark 2002;36:874-94.

Dewsnap B, Jobber D. An exploratory study of sales-marketing integrative devices. Eur J Mark 2009;43(7/8):985-1007.

Fiss P, Zajac E. The diffusion of ideas over contested terrain: the (non)adoption of a shareholder value orientation among German firms. Admin Sci Quart 2004;49 (4):501-34.

Gaski J. The theory of power and conflict in channels of distribution. J Mark 1984;48 (3):9-29.

Guenzi P, Troilo G. The joint contribution of marketing and sales to the creation of superior customer value. J Bus Res 2007;60(2):98-107.

Harris P, Moran R. Managing cultural differences. 2nd ed. Houston, TX: Gulf Publishing: 1987.

Hofstede G. Culture consequences: international differences in work-related values. Beverly Hills, CA: Sage; 1980.

Hofstede G. Cultures and organizations: software of the mind. New York: McGraw-Hill; 1991.

Homburg $C$, Jensen $\mathrm{O}$. The thought worlds of marketing and sales: which differences make a difference? J Mark 2007;71(7):124-42.

Homburg C, Jensen O, Krohmer H. Configurations of marketing and sales: a taxonomy. Mark 2008;72:133-54.

Huff L, Smith S. Cross-cultural business research: introduction to the special issue. J Bus Res 2008;61(3):179-82.

Hutt M. Cross-functional working relationships in marketing. J Acad Mark Sci 1995;23: 351-7.

Ingram T. Future themes in sales and sales management: complexity, collaboration, and accountability. J Mark Theory Prac 2004;12:18-28. (Fall).

Jarratt D, Fayed R. The impact of market and organizational challenges on marketing strategy decision-making: a qualitative investigation of the business-to-business sector. J Bus Res 2001;51(1):61-72.

Kniazeva M, Belk R. Supermarkets as libraries of postmodern mythology. J Bus Res 2010;63(7):748-53.

Kotler P, Rackham N, Krishnaswamy S. Ending the war between sales and marketing. Harv Bus Rev 2006;84:68-78.

Krohmer H, Homburg C, Workman J. Should marketing be cross-functional? Conceptual development and international empirical evidence. J Bus Res 2002;55(6): 451-65.

Kulviwat S, Bruner G, Al-Shuridah O. The role of social influence on adoption of high tech innovations: the moderating effect of public/private consumption. J Bus Res 2009;62(7):706-12
Laroche M. Introduction to the special issue on the impact of culture on marketing strategy. J Bus Res 2009;60(3):177-80.

Le Meunier-FitzHugh K, Piercy N. Does collaboration between sales and marketing affect business performance? J Pers Sell Sales Manage 2007;27:207-20.

Li J, Zhou K. How foreign firms achieve competitive advantage in the Chinese emerging economy: managerial ties and market orientation. J Bus Res 2010;63(8):856-62.

Lincoln Y, Guba E. Naturalistic inquiry. Beverly Hills, CA: Sage; 1985.

Liu S, Luo X, Shi Y. Market-oriented organizations in an emerging economy: a study of missing links. J Bus Res 2003;56(6):481-91.

Malshe A. How is marketers' credibility construed within the sales-marketing interface? J Bus Res 2010;63(1):13-9.

Malshe A, Sohi RS. What makes strategy making across the sales-marketing interface more successful? J Acad Mark Sci 2009a;37(4):400-21.

Malshe A, Sohi RS. Sales buy-in of marketing strategies: exploration of its nuances, antecedents, and contextual conditions. J Pers Sell Sales Manage 2009b;29(3): 207-25.

Maltz E. An enhanced framework for improving cooperation between marketing and other functions: the differential role of integrating mechanisms. J Mark Focus Manage 1997;2:83-98.

Matthyssens P, Johnston W. Marketing and sales: optimization of a neglected relationship. J Bus Ind Mark 2006;21:338-45.

McCracken G. The long interview. Newbury Park, CA: Sage; 1988.

Mcevers K. Saudis slow to accept working women. Marketplace 2008. Accessed fromhttp://marketplace.publicradio.org/display/web/2008/04/23/saudi_women/.

Muna F. The Arab Executive. New York: St. Martin's Press; 1980.

Oliva R. The three key linkages: improving the connections between marketing and sales. J Bus Ind Mark 2006;21:395-8.

Ouchi W. Markets, bureaucracies, and clans. Admin Sci Quart 1980;25(1):129-41.

Piercy N, Lane N. Transformation of the traditional sales force: imperatives for intelligence, interface and integration. J Mark Manage 2003;19(7):563-82.

Rouziès D, Anderson E, Kohli A, Michaels R, Weitz B, Zoltners A. Sales and marketing integration: a proposed framework. J Pers Sell Sales Manage 2005;25:113-22.

Rust R, Cooil. Reliability measures for qualitative data: theory and implications. J Mark Res 1994;31(1):1-14.

Strauss A, Corbin J. Basics of qualitative research. Newbury Park CA: Sage; 1990.

Tuli KR, Kohli AK, Bharadwaj SG. Rethinking customer solutions: from product bundles to relational processes. J Mark 2007;71(07):1-17.

Wang G, Netemeyer R. Salesperson creative performance: conceptualization, measurement, and nomological validity. J Bus Res 2004;57(8):805-12.

Yavas U, Cavusgil S, Tuncalp S. Assessments of selected foreign suppliers by Saudi importers: implications for exporters. J Bus Res 1987;15(3):237-46.

Zhou K, Li C. How strategic orientations influence the building of dynamic capability in emerging economies. J Bus Res 2010;63(3):2224-31. 